J. Lake Sci. (湖泊科学), 2005, 17(1): $24-27$

ISSN 1003 -5427; E-mail: jlakes@ niglas. ac.cn

Copyright 2005 by Journal of Lake Sciences

\title{
西藏扎布耶盐湖晚更新世沉积学及古气候意义*
}

李明慧 ${ }^{1,2}$, 郑绵平 ${ }^{1,2}$

(1:中国地质科学院矿产资源研究所,北京 100037)

(2:中国地质科学院盐湖与热水资源研究发展中心, 北京 100037)

摘 要: 从粘土矿物、碳酸盐矿物、狍粉、介形虫等方面,讨论了西藏扎布耶盐湖晚更新世的气候条件. $60.3 \pm 2.7 \mathrm{kaB} . \mathrm{P}$. 、 $142.2 \pm 7.4 \mathrm{kaB}$. P. 时期, 扎布耶为间或有一定盐度的淡水湖, 前期湖水含盐量比后期高. 气候寒冷, 风化作用不强, 物理 风化作用为主. 高岭石 $(60.3 \pm 2.7$ kaB. P. $)$ 和厌热性介形虫 Radix. Bowelli $(142.2 \pm 7.4$ kaB. P. $)$ 的出现说明, $142.2 \pm$ 7. $4 \mathrm{kaB}$. P. 时期气候偏干冷, 气温比现在低; $60.3 \pm 2.7 \mathrm{kaB}$. P. 气候偏湿冷. 比较方解石中 $\mathrm{Mg}$ 含量可知, $60.3 \pm 2.7 \mathrm{kaB}$. P. 比 $142.2 \pm 7.4 \mathrm{kaB}$. P. 的湖水盐度高.

关键词: 晚更新世; 阶地; 矿物; 扎布耶盐湖; 介形虫; 古气候

\section{Late Pleistocene Sedimentation and Palaeoclimate in Zabuye Saline Lake, Northwestern Ti- betan Plateau}

LI Minghui ${ }^{1,2} \&$ ZHENG Mianping ${ }^{1,2}$

(1:Institute of Mineral Resources, Chinese Academy of Geological Science (CAGS), Beijing 100037,P. R. China)

(2: Research \& Development Center of Saline Lake and Epithermal Deposites, CAGS, Beijing 100037, P. R. China)

\begin{abstract}
On the basis of clay, carbonate, pollen and ostracode, it presented the Late Pleistocene climate and environment of Zabuye saline lake in Northwestern Tibetan Plateau. In 60.3 $\pm 2.7 \mathrm{kaB}$. P. and $142.2 \pm 7.4 \mathrm{kaB}$. P., it was a freshwater lake. Weathering was weak and physical weathering dominated. In 60.3 $\pm 2.7 \mathrm{kaB}$. P. , the climate was cold and a little wet, as shown by the appearance of kalinite, and the salinity of water was higher than that of $142.2 \pm 7.4 \mathrm{kaB}$. P. On the contrary, the climate was cold and a little dry in $142.2 \pm 7.4 \mathrm{kaB}$. P. , and there were many whole shells of ostracodes which implies the water was relatively calm at that time. In addition, the Mg contents of calcite showed that the salinity of palaeo- Lake Zabuye during $60.3 \pm 2.7 \mathrm{kaB}$. P. was higher than in $142.2 \pm 7.4 \mathrm{kaB}$. P.
\end{abstract}

Keywords: Late Pleistocene; terrace; minerals; Lake Zabuye; ostracode; palaeoclimate

在全球环境变化研究中, 湖泊沉积物以其高分辨率、高连续性及其对气候与环境变化的高敏感性等优 点日益受到学者的重视. 气候变化造成湖泊退缩而留下许多古湖岸线即阶地, 是环境变化最直接的证据, 许多学者对此进行了研究 ${ }^{[1-5]}$. 湖泊研究中, 常用的代用指标有孢粉 ${ }^{[6,7]}$ 、介形虫 ${ }^{[8,9]}$ 、碳氧锶同位素等地球 化学 ${ }^{[10,11]}$ 、矿物学 ${ }^{[12]}$ 、轨道参数 ${ }^{[13]}$ 、模拟实验 ${ }^{[14]}$ 、年代学 ${ }^{[15,16]}$ 等. 目前, 西藏扎布耶盐湖晚更新世时期的 研究较少,本文主要从沉积学的角度进行分析.

扎布耶盐湖位于西藏自治区藏北高原中部 $\left(31^{\circ} 21^{\prime} \mathrm{N}, 84^{\circ} 04^{\prime} \mathrm{E}\right)$, 海拔 $4421 \mathrm{~m}$, 属于高原寒带干旱气候 区, 年均温 $1{ }^{\circ} \mathrm{C}$ 至 $-0.19^{\circ} \mathrm{C}$, 雨季集中在 $7 、 8$ 月, 其它为大风干旱季节. 日照充足, 昼夜温差大. 年降水量 $112-144.85 \mathrm{~mm}$, 年蒸发量 2274.92-2425 mm. 该湖属于冈底斯 - 念青唐古拉区的措勤 - 申扎地层分区. 白严纪㒸塘地块隆起, 冈底斯地区下沉, 接受了广泛的碳酸盐沉积, 位于冈底斯北部的扎布耶盐湖也接受了 大量碳酸盐沉积. 地层出露从老到新为:石炭系、二叠系、白严系、第三系和第四系. 第四系沉积物主要分布 在扎布耶盆地及边坡上, 主要为残坡积物、河流沉积、湖泊沉积和泉华.

扎布耶盐湖阶地和古湖滨线发育, 郑绵平 ${ }^{[1]}$ 等对砂堤等古湖岸线进行了详细研究 (图 1), 约 $30 \mathrm{kaB} . \mathrm{P}$. 
以来扎布耶湖一直退缩, 湖泊缩小, 矿化度增加. 本文取样剖面位置 (图 2) 在湖东北约 $40 \mathrm{~km}$ 处砂堤前缘出 露的一个冲沟内, 距离公路约百米, 周围有湖相沉积, 实测最高海拔高度为 $4593.4 \mathrm{~m}$ (图 1 中 A 点).

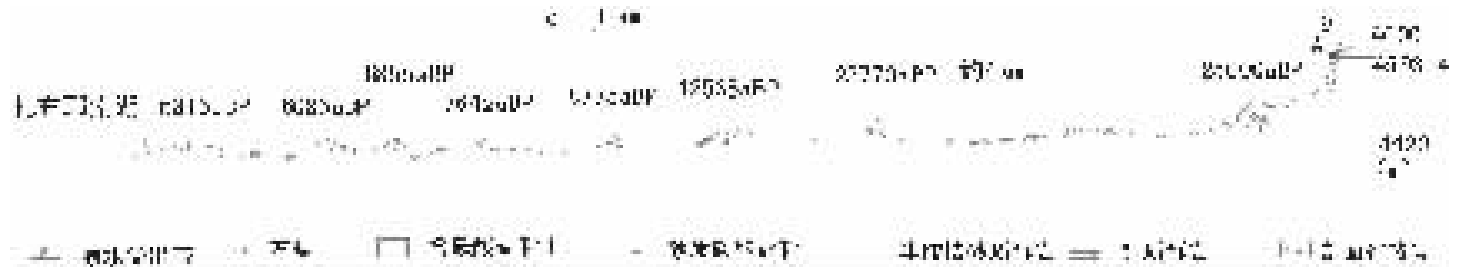

图 1 扎布耶砂堤地貌简图 ${ }^{[1]}$

Fig. 1 Geomorphological section of Lake Zabuye spits ${ }^{[1]}$

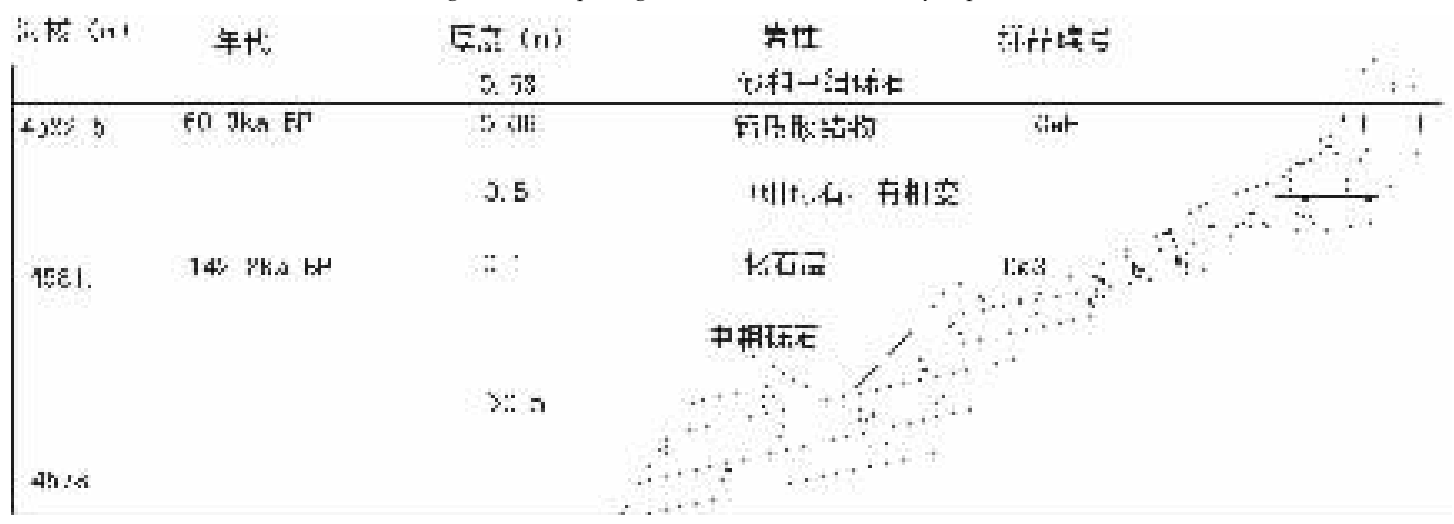

图 2 扎布耶湖取样剖面

Fig. 2 Sampling section of Lake Zabuye

\section{1 研究方法}

盐湖沉积物中含有较多的盐类矿物, 提取粘土矿物时, 先用蒸馏水反复冲洗, 直到溶液的 $\mathrm{pH}$ 值小于 8 , 然后再用一般粘土矿物方法提取, 分别进行自然片、乙二醇饱和片和 $550 \mathrm{oC}$ 加热片的 X 光扫描. 仪器型号 为 $\mathrm{D} / \mathrm{Max}-\mathrm{RC}$, 日本理学 Rigaku 制造; $\mathrm{CuK} \alpha: 50 \mathrm{KV}-70 \mathrm{~mA}$; 连续扫描速度: $4 \% \mathrm{~min}$; 石墨单色器, 闪㷧 (SC) 探测器, $K \alpha^{2}$ 剥离; 校正值: $2 \theta=0.002^{\circ}$; 起止角度 : $2 \theta=3-30^{\circ}$.

\section{2 结果及讨论}

\section{1 粘土矿物及其意义}

伊利石和绿泥石是岩石风化早期阶段的产物,冷干气候条件下由物理风化作用形成; 高岭石、蒙脱石则 是在相对温暖潮湿的环境下由化学风化作用形成 ${ }^{[17,18]}$. 扎布耶盐湖的粘土矿物主要是伊利石和绿泥石, 其 含量分别为 $60 \% 、 40 \%$, 这说明扎布耶盐湖主要是物理风化, 化学风化作用不强. $60.3 \pm 2.7 \mathrm{kaB}$. P. 的样品 出现了少量高岭石,与西藏其它盐湖区的粘土成分基本相同 ${ }^{[17]}$. 高岭石的出现,尽管少,但也说明在干旱 寒冷为主要特征的情况下,气候稍微有些湿润,气温稍微高些.

另外,阶地砾石特征也反映了较弱的物理风化作用. 显微照片中显示正在形成的绿泥石 (图略), 砾石 磨圆度多棱角、次棱角,说明砾石距物源区比较近,搬运距离不远. 伊利石和绿泥石主要是基性岩和含绿泥 石变质岩的低变质特征矿物 ${ }^{[18]}$, 根据周围的岩性情况判断, 伊利石和绿泥石的物质来源主要是盐湖南部和 西南部的白严系基性岩、西部和东部少量的第三系基性岩.

\section{2 碳酸盐矿物、化石及意义}

此处的碳酸盐矿物主要是生物、碎屑和无机沉淀形成的方解石和文石,方解石主要是低镁方解石; 生物 
碳酸盐主要来源于生物粪便 (棒状碳酸盐)、介形虫壳和腹足类壳.

根据镜下鉴定和 $X$ 射线分析, $60.3 \pm 2.7 \mathrm{kaB} . P$. 和 $142.2 \pm 7.4 \mathrm{kaB}$. P. 除粘土之外的其它矿物分别为: 方解石 $(\mathrm{Mg}$ 含量 $0.04 \%$ )、石英和少量长石, 碳酸盐含量为 $24.1 \%$; 石英、方解石 $(\mathrm{Mg}$ 含量 $0.0167 \%)$ 、斜长 石和文石, 碳酸盐含量为 $44 \%$. 据郑绵平等 ${ }^{[1]}$ 研究, $\mathrm{Mg}$ 含量小于 $1 \%$ 的为低镁方解石; 湖水含盐量越高, 低 镁方解石的出现率越低, 低镁方解石中 $\mathrm{Mg}$ 含量也越高. 比较方解石中 $\mathrm{Mg}$ 含量可知, $60.3 \pm 2.7 \mathrm{kaB} . \mathrm{P}$. 时 湖水含盐量比 $142.2 \pm 7.4 \mathrm{kaB}$. P. 时的高.

$60.3 \pm 2.7 \mathrm{kaB}$. P. 样品只出现一种介形虫 Limnocytherellina kunlunensis Pang一—广盐性种属 ${ }^{[11]}$; 介形虫 壳多破碎, 说明 $60 \mathrm{kaB}$. P. 左右时扎布耶湖水位相对动荡.

$142.2 \pm 7.4 \mathrm{kaB}$. P. 样品出现四种介形虫 (表 1), 介形虫壳保存完好, L. kunlunensis Pang 和 L. bispinosa Pang 数量较多, 后者的生活盐度为 $0.67-0.72 \mathrm{~g} / \mathrm{L}^{[19,20]}$, 而矿化度小于或等于 $1 \mathrm{~g} / \mathrm{L}$ 的湖泊为淡水湖 ${ }^{[21]}$, 所以, 当时的扎布耶湖为淡水湖, 湖水相对平静. Leucocythere sp. 和 Candoniella mirabilis Schneider 含量较 少, 前者为广盐性和广温性种属, 无指示意义; 后者是一种厌热性种属, 生活在 $10^{\circ} \mathrm{C}$ 以下的环境中.

表 1 粘土、U 系法年代、化石分析结果

Tab. 1 Clays, U - Series chronolgy and fossils

\begin{tabular}{clcl}
\hline 样品编号 & 粘土矿物 & 年代 $(\mathrm{kaB} . \mathrm{P})$. & 介形虫和腹足类化石 \\
\hline $\mathrm{CaE}$ & $\begin{array}{l}\text { 伊利石 }(60 \%) 、 \text { 绿 } \\
\text { 泥石、少量高岭石 }\end{array}$ & $60.3 \pm 2.7$ & Limnocytherellina kunlunensis Pang \\
\hline $\mathrm{Ca}(3)$ & $\begin{array}{l}\text { 伊利石 }(60 \%) 、 \text { 、绿 } \\
\text { 泥石 }(40 \%)\end{array}$ & $142.2 \pm 7.4$ & $\begin{array}{l}\text { L. kunlunensis Pang、L. bispinosa Pang、Leucocythere } \text { sp. Candoniel- } \\
\text { la mirabilis Schneider; 腹足类化石:Radix cucunorica、R. bowelli }\end{array}$ \\
\hline
\end{tabular}

$142.2 \pm 7.4$ kaB. P. 样品中还出现了腹足类 Radix. Bowelli 化石, 该化石在中国境内只出现在西藏. 研 究表明,腹足类壳体碳酸盐是在与宿生水体处于同位素平衡状态下形成的,生物壳体碳酸盐同位素高低变 化记录了生物体形成时的气候环境信息 ${ }^{[22,23]}$. 兴措湖 $\left(102^{\circ} 20^{\prime}-102^{\circ} 24^{\prime} \mathrm{E}, 33^{\circ} 54^{\prime}-33^{\circ} 50^{\prime} \mathrm{N}\right)$ 出现腹足类 Gyraulus sibirica, 对其壳体碳氧同位素研究发现,这种生物一般在温季生长,记录温季而不是全年的气候信 息,对应夏半年平均气温为 $7.4^{\circ} \mathrm{C}^{[22]}$. 虽然二者种属不同,由于样品数量较少本文也没有做同位素方面的 工作, 但是, 同处于青藏高原的环境中,再结合介形虫 Candoniella mirabilis Schneide 的生活温度, 可以简单推 断,Radix. Bowelli 生活的水体温度也不高, $10^{\circ} \mathrm{C}$ 以下. 另外,据扎布耶湖的实测资料, $1991-1994$ 年扎布耶 盐湖最热季节 6-9 月份水温为 $9-15^{\circ} \mathrm{C}$. 综上所述, 可以推断 $142.2 \pm 7.4 \mathrm{kaB}$. P. 时扎布耶湖水温度比现 在低,湖区气候比现在冷.

孢粉分析发现, $60.3 \pm 2.7 \mathrm{kaB}$. P. 出现盘星藻一一可以忍耐一定盐度的典型淡水藻 ${ }^{[24,6]}$, 说明当时扎 布耶为淡水湖. $60.3 \pm 2.7 \mathrm{kaB}$. P. 和 $142.2 \pm 7.4 \mathrm{kaB}$. P. 时植被均以草本科为主, 含量分别为 $97.52 \%$ (628 粒 $/ g$ ) 和 $95.89 \%$ (746 粒 $/ g$ ), 蒿属占绝对优势, 分别为 $93.17 \%$ (600 粒 $/ g$ ) 和 $89.97 \%(700$ 粒 $/ \mathrm{g})$, 还出现了 藜科、莎草科及蓱类植物等 (表 $2 、 3$ ). 植被类型的确定一般以优势花粉为主要依据, 本剖面草本植物含量 超过 $90 \%$, 其中的蒿属又占草本花粉的 $90 \%$ 左右, 蒿属是荒漠草原或小半灌木荒漠的主要成分, 但确定荒

表 2 孢粉百分含量

Tab. 2 Percents of pollen (\%)

\begin{tabular}{cccccccccc}
\hline 编号 & 木本花粉 & 草本花粉 & 莎草科 & 蒿 & 禾本科 & 松属 & 藜科 & 厥类 & 盘星藻 \\
\hline $\mathrm{CaE}$ & 2.17 & 97.52 & 0.31 & 93.17 & 1.39 & 1.86 & 0.466 & 0.31 & 有 \\
$\mathrm{Ca} 3$ & 3.72 & 95.89 & 2.44 & 89.97 & 1.03 & 1.8 & 0.8997 & 0.39 & 无 \\
\hline
\end{tabular}

表 3 孢粉浓度 (粒/g)

Tab. 3 Concentration of pollen

\begin{tabular}{|c|c|c|c|c|c|c|c|c|c|c|}
\hline 编号 & $\begin{array}{c}\text { 孢粉总 } \\
\text { 浓度 }\end{array}$ & $\begin{array}{l}\text { 狍粉 } \\
\text { 总数 }\end{array}$ & $\begin{array}{l}\text { 木本 } \\
\text { 花粉 }\end{array}$ & $\begin{array}{l}\text { 草本 } \\
\text { 花粉 }\end{array}$ & $\begin{array}{l}\text { 蕨类 } \\
\text { 狍子 }\end{array}$ & 松属 & $\begin{array}{l}\text { 禾本 } \\
\text { 科 }\end{array}$ & 蒿 & $\begin{array}{l}\text { 莎草 } \\
\text { 科 }\end{array}$ & 藜科 \\
\hline $\mathrm{CaE}$ & 4398.46 & 644 & 14 & 628 & 2 & 12 & 9 & 600 & 2 & 3 \\
\hline $\mathrm{Ca}(3)$ & 3871.38 & 778 & 29 & 746 & 3 & 14 & 8 & 700 & 19 & 7 \\
\hline
\end{tabular}


漠草原的另一个条件是草本植物花粉浓度低于 100 粒/ $\mathrm{g}^{[25,6]}$, 由表 3 可以看出, 无论花粉总浓度或草本花 粉浓度都不低. 由于此处孢粉样品数量有限, 结合内部资料及萧家仪等 ${ }^{[24]}$ 研究结果, 可以初步判断当时扎 布耶湖可能为基质、水分条件稍好些的半荒漠化草原植被.

致谢 感谢刘俊英研究员对介形虫样品处理的帮助和卜令忠工程师对野外工作的支持. 矿物实验在中国 地质大学完成. U 系法测年由中国科学院地质与地球物理所马志邦副研究员完成, 孢粉由中国地质科学院 水文地质所童国榜研究员完成, 介形虫鉴定由河北经济研究院庞其清研究员完成, 在此一并致谢.

\section{3 参考文献}

[1] 郑绵平,向 军. 青藏高原盐湖. 北京: 北京科学技术出版社, 1989:192-219.

[2] 陈克造, Bowler J M, Kelts K. 四万年来青藏高原的气候变迁. 第四纪研究, 1990, (1):21 - 30.

[3] 李世杰,郑本兴, 焦克勤. 西昆仑山南坡湖泊沉积演化的初步研究. 地理科学, 1991,11(4):306-313.

[4] Van Campo E, Gasse F. Pollen-and diatom-inferred climatic and hydrological changes in Samxi Co basin (western Tibet) Since 13000yr BP. Quaternary Research, 1993,39:300 - 313.

[5] Rhodes T E, Gasse F, Ruifen L, et al. A Late Pleistocene-Holocene lacustrine record from Lake Manas, Zunggar( northern Xinjiang, western China). Palaeogeography, Palaeoclimatology, Palaeoocology, 1996, 120 (1 -2) :118.

[6] 沈才明, 唐领余, 王苏民. 若尔盖地区 25 万年以来的植被与气候. 微体古生物学报, 1996,14(4):373-385.

[7] 朱浩然,曾昭琪,张忠英. 江苏北部下第三系戴南组盘星藻化石及其沉积环境的初步分析. 古生物学报, 1978,17 (2) :242.

[8］李元芳,李炳元,王 国. 西昆仑山甜水海古湖介形虫类及其环境意义. 湖泊科学, 1997,9(3):223-229.

[9] 刘俊英, 郑绵平, 齐 文. 西藏扎布耶盐湖 $40 \mathrm{kaB}$. P. 以来微体古生物与气候环境演变. 见: 庆祝中国地质学会成立 80 周年学术讨论会文集,2002: 560-566.

[10] 金章东,王苏民,沈 吉等. 湖泊沉积物 Sr 同位素记录的小冰期. 科学通报, 2002,47(19) :1512-1516.

[11] Cross S L, Baker P A, Seltzer G O, et al. Late Quaternary climate and hydrology of tropical south America inferred from an isotopic and chemical model of Lake Titicaca, Bolivia and Peru. Quaternary Research ,2001,56:1 - 9.

[12] Wirrmann D, Bertaux J, Kossoni A. Late Holocene paleoclimatic changes in Western Central Africa inferred from mineral abundance in dated sediments from Lake Ossa(Southwest Cameroon). Quaternary Research ,2001,56:275 - 287.

[13] Van Vugt N, Langereis C G, Hilgen F J. Orbital forcing in Pleistocene Mediterranean lacustrine deposits: dominant expression of eccentricity versus precession. Palaeogeography, Palaeoclimatology, Palaeoocology, 2001, 172 : 193 - 205.

[14] Ganopolski A, Rahmstorf S. Rapid changes of glacial climate simulated in a coupled climate model. Nature, 2001,409: $245-248$.

[15] 马志邦,赵希涛, 朱大岗等. 西藏纳木错湖相沉积的铀系年代学研究. 地球学报, 2002,23(4):311-316.

[16] Lang A, Zolitschka B. Optical dating of annually laminated lake sediments: a test case from Holzmaar, Germany. Quaternary Science Reviews, $2001,20: 737-742$.

[17] 徐 昶. 我国盐湖粘土矿物研究进展. 盐湖研究, 1993,1(2):72 - 77 .

[18 ] Ehrmann W. Implications of late Eocene to early Miocene clay mineral assemblages in McMurdo Sound(Ross Sea, Antarctica) on paleoclimate and ice dynamics. Palaeogeography, Palaeoclimatology, Palaeoecology, 1998, 139:213 - 231.

[19］庞其清. 青藏高原昆仑山口更新世介形类的一新属. 见: 青藏高原地质文集, 16. 北京: 地质出版社, $1985: 269$ $-276$.

[20］李元芳,张青松,李炳元. 青藏高原西部 17000 年以来的介形类及环境演变. 地理学报, 1994,49(1):46-53.

[21] 郑喜玉,徐 昶,张明刚等著. 中国盐湖志, 北京:科学出版社, 2002:3-8

[22] 吴敬禄, Andreas Lucke, 李世杰等. 青藏高原兴措湖腹足类壳体同位素组成特征与环境意义. 古生物学报, 2003,42 (2) : $292-296$.

[23] Bowen R. Isotopes and climates. London and New York: Elservier Applied Science, 1990:140 - 175.

[24] 萧家仪, 吴玉书, 郑绵平. 西藏扎布耶盐湖晚第四纪狍粉植物群的初步研究. 微体古生物学报, 1996,13 (4):395 -399 .

[25] 许清海, 阳小兰,王子惠等. 晚更新世晚期以来昆仑山垭口区的植被与环境. 微体古生物学报, 1996,13 (4):387 -393 . 